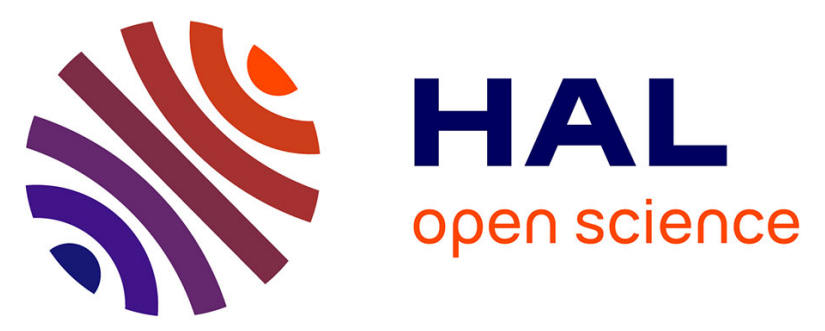

\title{
Relationship between childhood physical abuse and clinical severity of treatment-resistant depression in a geriatric population
}

Antoine Yrondi, Christophe Arbus, Djamila Bennabi, Thierry D'amato, Frank Bellivier, Thierry Bougerol, Vincent Camus, Philippe Courtet, Olivier Doumy, Jean-Baptiste Genty, et al.

\section{To cite this version:}

Antoine Yrondi, Christophe Arbus, Djamila Bennabi, Thierry D'amato, Frank Bellivier, et al.. Relationship between childhood physical abuse and clinical severity of treatment-resistant depression in a geriatric population. PLoS ONE, 2021, 16 (4), pp.e0250148. 10.1371/journal.pone.0250148 . hal-03239839

\section{HAL Id: hal-03239839 \\ https://hal-univ-paris.archives-ouvertes.fr/hal-03239839}

Submitted on 27 May 2021

HAL is a multi-disciplinary open access archive for the deposit and dissemination of scientific research documents, whether they are published or not. The documents may come from teaching and research institutions in France or abroad, or from public or private research centers.
L'archive ouverte pluridisciplinaire HAL, est destinée au dépôt et à la diffusion de documents scientifiques de niveau recherche, publiés ou non, émanant des établissements d'enseignement et de recherche français ou étrangers, des laboratoires publics ou privés.

\section{(c)(1)}

Distributed under a Creative Commons Attribution| 4.0 International License 


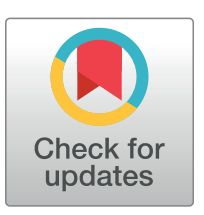

\section{f open AcCEss}

Citation: Yrondi A, Arbus C, Bennabi D, D'Amato T, Bellivier F, Bougerol T, et al. (2021) Relationship between childhood physical abuse and clinical severity of treatment-resistant depression in a geriatric population. PLoS ONE 16(4): e0250148. https://doi.org/10.1371/journal.pone.0250148

Editor: Marco Innamorati, Universita degli Studi Europea di Roma, ITALY

Received: January 5, 2021

Accepted: April 1, 2021

Published: April 20, 2021

Copyright: ๑ 2021 Yrondi et al. This is an open access article distributed under the terms of the Creative Commons Attribution License, which permits unrestricted use, distribution, and reproduction in any medium, provided the original author and source are credited.

Data Availability Statement: All relevant data are within the manuscript and its Supporting Information files.

Funding: This research was funded by the Foundation FondaMental, Institut National de la Santé et de la Recherche Médicale (INSERM), AP$\mathrm{HP}$, Astra Zeneca, and by the Investissements d'Avenir program managed by the ANR under reference ANR-11-IDEX-0004-02. This funding source had no role in the study design, data

\section{Relationship between childhood physical abuse and clinical severity of treatment- resistant depression in a geriatric population}

\author{
Antoine Yrondi $\mathbb{D}^{1,2} *$, Christophe Arbus ${ }^{1,2}$, Djamila Bennabi ${ }^{1,3}$, Thierry D'Amato ${ }^{1,4}$, \\ Frank Bellivier ${ }^{1,5}$, Thierry Bougerol ${ }^{1,6}$, Vincent Camus ${ }^{1,7}$, Philippe Courtet ${ }^{1,8}$, \\ Olivier Doumy ${ }^{1,9}$, Jean-Baptiste Genty ${ }^{1,10}$, Jérôme Holtzmann ${ }^{1,6}$, Mathilde Horn ${ }^{1,11}$, \\ Christophe Lancon $^{1,12}$, Marion Leboyer ${ }^{1,10}$, Pierre-Michel Llorca ${ }^{1,13}$, Julia Maruani ${ }^{1,5}$, \\ Rémi Moirand ${ }^{1,4}$, Fanny Molière ${ }^{1,8}$, Jean Petrucci ${ }^{1,10}$, Raphaelle Richieri ${ }^{1,12}$, \\ Ludovic Samalin $^{1,13}$, Florian Stephan ${ }^{1,14}$, Guillaume Vaiva ${ }^{1,15}$, Michel Walter ${ }^{1,14}$, \\ FondaMental Advanced Centres of Expertise in Resistant Depression (FACE-DR) \\ Collaborators", Emmanuel Haffen ${ }^{1,3}$, Bruno Aouizerate ${ }^{1,9 \ddagger}$, Wissam El-Hage ${ }^{1,7 \ddagger}$
}

1 Fondation FondaMental, Creteil, France, 2 Service de Psychiatrie et de Psychologie Médicale de l'adulte (Department of Psychiatry and Adult Medical Psychology), Centre Expert Dépression Résistante FondaMental (FondaMental Advanced Centre of Expertise in Resistant Depression, CHU de Toulouse (University Hospital Centre), Hôpital Purpan, ToNIC Toulouse Neurolmaging Centre, Université de Toulouse (Toulouse University), INSERM, UPS, Toulouse, France, 3 Service de Psychiatrie, Centre Expert Dépression Résistante FondaMental, CIC-1431 INSERM, CHU de Besançon, Université de Bourgogne Franche Comté, Besançon, France, 4 INSERM U1028; CNRS UMR5292; University Lyon 1, Villeurbanne, F-69000, France; Lyon Neuroscience Research Centre; Psychiatric Disorders: From Resistance to Response $\Psi$ R2 Team; Centre Hospitalier Le Vinatier (Hospital Centre); Bron, France, 5 AP-HP, GH Saint-Louis—Lariboisière-Fernand Widal, Pôle Neurosciences Tête et Cou (Head and Neck Neurosciences Cluster), University Paris Diderot, Paris, France, 6 Université Grenoble Alpes, Inserm, U1216, CHU Grenoble Alpes, Grenoble Institut Neurosciences (Institute of Neurosciences), Grenoble, France, 7 U1253, iBrain, CIC1415, Inserm, CHRU de Tours (Regional University Hospital Centre), Université de Tours, Tours, France, 8 Department of Emergency Psychiatry and Acute Care, CHU Montpellier, INSERM U1061, Montpellier University, Montpellier, France, 9 Pôle de Psychiatrie Générale et Universitaire (General and University Psychiatry Cluster), Centre Expert Dépression Résistante FondaMental, CH Charles Perrens, Bordeaux, Laboratoire Nutrition et Neurobiologie intégrée (Integrated Nutrition and Neurobiology Laboratory) (UMR INRAE 1286), Université de Bordeaux (Bordeaux University), Bordeaux, France, 10 Université Paris-Est, UMR_S955, UPEC, Créteil, France Inserm, U955, Equipe 15 Psychiatrie génétique (Team 15 Genetic Psychiatry), Créteil, France AP-HP, Hôpital H. Mondor-A. Chenevier, Pôle de psychiatrie (Psychiatry Cluster), Créteil, France Fondation FondaMental, Fondation de Cooperation Scientifique (Scientific Cooperation Foundation), Créteil, France, 11 Service de Psychiatrie adulte (Department of Adult Psychiatry), Centre Expert Dépression Résistante FondaMental, CHRU de Lille, Hôpital Fontan 1, Lille, France, 12 Pôle Psychiatrie, Centre Expert Dépression Résistante FondaMental, CHU La Conception, Marseille, France, 13 Department of Psychiatry, CHU Clermont-Ferrand, University of Clermont Auvergne, Clermont-Ferrand, France, 14 Service Hospitalo-Universitaire de Psychiatrie Générale et de Réhabilitation Psycho Sociale 29G01 et 29G02 (University Hospital Department of General Psychiatry and Psychosocial Rehabilitation), Centre Expert Depression Résistante FondaMental, CHRU de Brest, Hôpital de Bohars, Brest, France, 15 Centre National de Ressources et Résilience pour les psychotraumatisme (National Resilience and Resources Centre for Psychological Trauma), Lille, France

$\ddagger$ These authors co-last authors on this work.

ๆ Membership of, FondaMental Advanced Centres of Expertise in Resistant Depression (FACE-DR) is provided in the Acknowledgments.

* antoineyrondi@gmail.com

\section{Abstract}

\section{Introduction}

We assessed the correlation between childhood maltreatment (CM) and severity of depression in an elderly unipolar Treatment-Resistant Depression (TRD) sample. 
collection, analysis, manuscript preparation or decision to submit the manuscript for publication.

Competing interests: Antoine Yrondi received speaker's honoraria (AstraZeneca, Janssen, Lundbeck, Otsuka, Servier), and carried out clinical studies in relation to the development of a medicine (Janssen, Lundbeck) unrelated to this work. Christophe Arbus received honoraria (Janssen, Lundbeck, Otsuka) and carried out clinical studies in relation to the development of a medicine (Janssen). Olivier Doumy received honoraria from Lilly, Astra-Zeneca, Janssen, Servier and Lundbeck. Jean Baptiste Genty received speaker's honoraria from Servier. Pierre Michel Llorca received grants, honoraria, and consulting fees from Allergan, Gedeon Richter, Janssen-Cilag, Lundbeck, Otsuka, Recordati, Sanofi-Aventis and Teva. Raphael Rachieri received speaker's honoraria from Janssen Cilag. Ludovic Samalin received grants, honoraria, and consulting fees from Janssen-Cilag, Lundbeck, and Otsuka. Florian Stephan received honoraria from Otsuka. Guillaume Vaiva received speaker's honoraria from Otsula/Lundbeck (Annual participation at the reception day for new professors of psychiatry). Emmanuel Haffen: acted in an advisory capacity, carried out clinical studies in relation to the development of a medicine, received personal research, study or travel allowances, gave presentations at meetings, and received remuneration for input from the following pharmaceutical organisations: AstraZeneca, BMS Cellgene, Euthérapie - Servier, Janssen, Elli Lilly, Lundbeck, LivaNova, Otsuka, Pfizer and Sanofi. He also held a managerial position at the FondaMental Foundation (Créteil) and the French Association of Biological Psychiatry and

Neuropsychopharmacology. Wissam El-Hage has received speaker's honoraria from Chugai, Eisai, Lundbeck, Janssen-Cilag, Otsuka, and UCB unrelated to this work. Bruno Aouizerate received speaker's honoraria and a travel allowance from Lundbeck, Janssen-Cilag, and Eli Lilly. He has served on the advisory board of Janssen-Cilag. Our compeing interest does not alter our adherence to PLOS ONE policies on sharing data and materials.

Abbreviations: BFI, Big Five Inventory; BMI, Body Mass Index; CM, Childhood Maltreatment; CTQ Childhood Trauma Questionnaire; DSM, Diagnostic and Statistical Manual of Mental disorders; EA, Emotional Abuse; EN, Emotional Neglect; EOD, Early Onset Depression; FACE-DR, French Network of Expert Centres for Resistant Depression; LOD, Late Onset Depression; MADRS, MontgomeryÅsberg Depression Rating Scale; MDD, Major Depressive Disorder; MINI, Mini International

\section{Methods}

Patients were enrolled from a longitudinal cohort (FACE-DR) of the French Network of Expert TRD Centres.

\section{Results}

Our sample included 96 patients ( $33 \%$ of the overall cohort) aged 60 years or above, with a mean age of $67.2(S D=5.7)$. The majority of the patients were female $(62.5 \%)$. The Montgomery and Asberg Depression Rating Scale (MADRS) and Quick Inventory Depression Scale-Self Report (QIDS-SR) mean scores were high, 28.2 (SD = 7.49) [MADRS score range: $0-60$; moderate severity $\geq 20$, high severity $\geq 35$ ] and $16.5(S D=4.94)$ [IDS-SR score range: $0-27$; moderate severity $\geq 11$, high severity $\geq 16$ ], respectively. Mean self-esteem scores were 22.47 (SD = 6.26) [range 0-30]. In an age- and sex-adjusted model, we found a positive correlation between childhood trauma (CTQ scores) and depressive symptom severity [MADRS $(\beta=0.274 ; p=0.07)$ and QIDS-SR $(\beta=0.302 ; p=0.005)$ scores]. We detected a statistically significant correlation between physical abuse and depressive symptom severity [MADRS ( $\beta=0.304 ; p=0.03$ ) and QIDS-SR $(\beta=0.362 ; p=0.005)$ scores]. We did not observe any significant correlation between other types of trauma and depressive symptom severity. We showed that self-esteem (Rosenberg scale) mediated the effect of physical abuse (PA) on the intensity of depressive symptoms [MADRS: $b=0.318,95 \% \mathrm{BCa}$ C.I. [0.07, 0.62]; QIDS-SR: $b=0.177,95 \%$ BCa C.I. [0.04, 0.37]]. Preacher \& Kelly's Kappa Squared values of $19.1 \%\left(k^{2}=0.191\right)$ and $16 \%\left(k^{2}=0.16\right)$, respectively for the two scales, indicate a moderate effect.

\section{Conclusion}

To our knowledge, this is the first study conducted in a geriatric TRD population documenting an association between childhood trauma (mainly relating to PA) and the intensity of depressive symptoms.

\section{Introduction}

Depression is a very common disorder in the elderly, with a prevalence of up to $30 \%$ [1].

Geriatric depression is currently defined as the occurrence of depressive episodes in the elderly, although the age at onset is critical, with early- (EOD; first episode before the age of 60 ) or late-onset depression (LOD; first episode after the age of 60). Some differences have been reported between EOD and LOD [2-4]. For instance, personality abnormalities and a family history of psychiatric illness were significantly more common in EOD [3, 4]. However, when the severity, phenomenology, history of previous episodes, and neuropsychological performance were considered, no difference was found between EOD and LOD in elderly people $[3,4]$. As shown by van Krugten et al., an older age, a high severity, a poor treatment response and childhood trauma should be sought due to their association with need for highly specialized Major Depressive Disorder (MDD) care [5].

Half of elderly depressed adults report some form of childhood abuse [6]. Childhood mistreatment is associated with the development of geriatric depression, albeit more frequently in EOD $[1,6]$. There is also a link between childhood abuse and EOD in older populations [7]. In 
Neuropsychiatric Interview; PA, Physical Abuse; PN, Physical Neglect; QIDS-SR, Quick Inventory of Depressive Symptomatology-Self Report; SA, Sexual Abuse; SD, Standard Deviation; TRD, Treatment Resistant Depression. addition, the relationship between childhood maltreatment and geriatric depression (EOD or LOD) is mediated by certain personality traits. Neuroticism and extraversion seem to be more direct mediators while agreeableness and conscientiousness are rather indirect mediators [1]. However, none of these previous studies specifically examined the link between childhood trauma and treatment-resistant depression (TRD) in the context of a geriatric population. TRD is currently defined by the failure of at least two attempted antidepressant treatments administered sequentially, at adequate dose, and for an adequate duration [8]. It can be assumed that approximately 20 to $30 \%$ of depressed patients experience TRD, as reported in Anglo-Saxon countries [9], and up to one-half of patients respond only partially [8]. TRD has been estimated to represent half of the overall treatment costs for MDD [10, 11]. Specific care packages exist for TRD in an elderly population [12]. To date, there has been little investigation examining the associations between childhood adversity and TRD. Kaplan \& Klinetob [13] compared a TRD population to a population that responded successfully to antidepressants. They reported greater levels of childhood emotional abuse in the TRD group. Tunnard et al. [14] focused on TRD, although the unipolar and bipolar populations were mixed. They showed that childhood adversity was common among these TRD patients (62\%) and was associated with poor clinical course, characteristics of psychosis, and suicide attempts. However, to our knowledge, no study has focused on childhood trauma and TRD in a geriatric population.

Moreover, self-esteem is associated with the clinical symptomatology and prognosis in geriatric depression. Indeed, firstly, it has been found that low self-esteem significantly increases the risk of suicidal behaviour [15]. Secondly, depressive symptoms are negatively correlated with self-esteem in this population [16]. In addition, patients with low self-esteem respond more slowly to antidepressant treatment compared to their counterparts with higher selfesteem [17].

In young adults, the association between childhood maltreatment or bullying and mental health, in particular depression, has now been well-documented in large cohorts (The Quebec Longitudinal Study of Child Development, the Avon Longitudinal Study of Parents and Children in the UK, the Great Smoky Mountains Study in the USA) [18, 19]. However, in contrast, data focusing on this association in the elderly population still remain scarce.

Thus, we posit the hypothesis that there is an association between childhood maltreatment (CM) and the severity of depression, specifically in an elderly TRD population. Moreover, given the role of personality traits as well as self-esteem in the symptomatology and course of the depressive disorder $[20,21]$, we postulate that personality traits and self-esteem could mediate the association between CM and the severity of depressive symptoms.

Therefore, our first objective is to assess the potential association between CM and the severity of depression. Our second objective is to investigate whether personality traits and self-esteem could influence the association between CM and the severity of depressive symptoms.

\section{Materials and methods}

Populations: Patients were recruited for a prospective cohort (FACE-DR cohort) from the French Network of Expert Centres for Resistant Depression, consisting of 13 specialist care centres operating from within academic psychiatry departments across France [22, 23]. The recruitment for this analysis took place from July 2012 to December 2018.

The patients were clinically unresponsive to at least two successive, adequate attempts of antidepressant treatment from two different pharmacological classes, corresponding to at least stage II of the staging criteria proposed by Thase \& Rush for defining TRD [24]. We selected all the cohort patients over 60 years of age for this study. Although the cut-off between geriatric 
and non-geriatric depression remains unclear, ranging from $60[1,7,25,26]$ to 65 years old $[27,28]$, we chose the age of 60 in order to compare our findings with those of the majority of studies focusing on the impact of CM in depressive disorders [1, 7, 25, 26]. Before participating in the full assessment, the patients were interviewed by a psychiatrist at the expert centre in order to:

- Confirm the diagnosis of TRD according to the DSM-IV (MINI) [29] criteria, with moderate to severe symptoms, the level of resistance being indicated by a Thase \& Rush classification of $\geq 2$ [24]. Since the recruitment started in 2012, we used the standard DSM-IV criteria for MDD.

- Exclude bipolar disorders, psychotic disorders, obsessive-compulsive disorders, eating disorders (with BMI < 15), somatoform disorders and mood disorders related to substance abuse or misuse.

- Inform the patient about the formal assessment procedure.

Assessment: We selected patients who were 60 or over and clinically resistant to medications as determined by the Thase \& Rush staging criteria (i.e. level II) [22, 24]. The severity of depressive symptoms, CM, self-esteem and personality traits were assessed using the Montgomery-Åsberg Depression Rating Scale (MADRS) [30], the Quick Inventory of Depressive Symptomatology Self-Report (QIDS-SR) [31], the Childhood Trauma Questionnaire (CTQ) [32], the Rosenberg scale [33] and the Big Five Inventory (BFI) [34], respectively. The MADRS is a ten-item, hetero-questionnaire currently used to measure the severity of depressive episodes in patients with mood disorders. Scores range from 0 to 60 [30]. The QIDS-SR is a selfrating clinical instrument derived from the 30-item Inventory of Depressive Symptomatology. It asks 16 questions in order to assess the severity of the nine diagnostic symptom criteria used in DSM. These nine criterion-related symptoms do not assess anxious, atypical or melancholic features or other commonly associated symptoms such as pain or gastrointestinal disturbances. Scores range from 0 to 27 [31]. The CTQ is a screening tool for history of abuse and neglect. The self-report includes a 28 -item scale that measures 5 types of maltreatment-emotional, physical and sexual abuse, and emotional and physical neglect [32]. The Rosenberg scale determines global self-worth by measuring both positive and negative feelings about oneself. Scores range from 0 to 30 [33]. The BFI is a self-reported inventory designed to measure the Big Five dimensions: neuroticism, extraversion, agreeableness, openness and conscientiousness. It is a 44-item multidimensional personality inventory [34].

The authors hereby confirm that all work-related procedures comply with the ethical standards of the relevant national and institutional committees on human experimentation and with the Helsinki Declaration of 1975, as revised in 2008. The assessment protocol was approved by the relevant institutional review board [French CNIL (French Data Protection Authority): DR-2015-673]. The consent obtained from study participants was written and verbal.

\section{Statistical analysis}

Sociodemographic and clinical characteristics were presented using means and standard deviations for continuous variables, and frequency distributions for categorical variables. The chisquare test was used to compare categorical variables, and the t-test and ANOVA to compare continuous variables. Linear regression models were applied to test the association between dependent variables (MADRS, QIDS-SR) and independent variables (CTQ and subtypes, BFI subtypes, Rosenberg scale). Linear regression models were adjusted for age and sex. We used 
the Hayes mediation model [35] in the cross-sectional study to assess the influence of one variable on the association between CM and intensity of depressive symptoms at a specific time point. Mediation was deemed partial when indirect and direct effects were both statistically significant, and it was considered to be complete when only the indirect effect was statistically significant. Bonferroni correction was applied for multiple comparisons (CM subtypes). Statistical analyses were performed with SPSS 25.0 (IBM Corp. Released 2017. IBM SPSS Statistics for Mac, Version 25.0. Armonk, NY: IBM Corp.).

\section{Results}

\section{Demographic and clinical data}

Our study included 96 patients (Table 1) (33\% of the overall cohort) with a mean age of 67.2 [standard deviation (SD): 5.7] and a majority of women (62.5\%). In our sample, 82 patients (85.4\%) completed the CTQ [mean score: 37.35 (SD: 9.69)]. The MADRS and QIDS-SR mean scores were high, reflecting severe depression. There was no difference in the intensity of depression symptoms on comparing the difference in terms of marital status (Table 2). A Rosenberg mean score of 22.47 (SD: 6.26) was documented. The BFI scores were: neuroticism [mean: 3.85 (SD: .63)], extraversion [mean: 2.37 (SD: .83)], agreeableness [mean: 4.14 (SD: .46)], openness [mean: 2.8 (SD: .86)] and conscientiousness [mean: 3.5 (SD: .75)]. LOD (i.e. the first episode after 60 years of age) affected 25 patients (26\%). A significant difference between EOD [8.66 (SD: 4.44)] and LOD [6.48 (SD: 1.54)] was noted in relation to PN $(\mathrm{p}=0.025)$ (Fig 1). However, we did not find any difference between LOD and EOD in relation to (i) other CM; (ii) the severity of depressive symptoms and (iii) self-esteem (Table 1).

\section{Relationship between childhood maltreatment and depressive symptom severity}

The regression analysis found a significant positive association between CM and the intensity of depressive symptoms throughout our study sample of elderly TRD patients (Table 3 ). In an adjusted model (age and gender), CTQ scores were positively associated with MADRS ( $\beta=$ $0.274 ; \mathrm{p}=0.07)$ and QIDS-SR $(\beta=0.302 ; \mathrm{p}=0.005)$ scores (Fig 2). In relation to physical abuse $(\mathrm{PA})$, we highlighted a significant association with MADRS $(\beta=0.304 ; \mathrm{p}=0.03)$ and QIDS-SR $(\beta=0.362 ; \mathrm{p}=0.005)$ scores (Fig 3$)$. We did not, however, detect any significant association between other types of CM and the intensity of depressive symptoms (Table 3 ).

\section{Influence of personality traits on the relationship between childhood maltreatment and depressive symptom severity}

We found no significant correlation between CM and personality traits (Table 4). Nor did we find any significant associations between distinct subtypes of CM and personality traits.

\section{Influence of self-esteem on the relationship between childhood maltreatment and depressive symptom severity}

In an adjusted model, we found a negative association between CM (CTQ total) and selfesteem $(\beta=-0.25 ; \mathrm{p}=0.036)$, specifically in cases reporting PA $(\beta=-0.32 ; \mathrm{p}=0.04)$ (Table 5$)$. Our objective was to assess the potential role of self-esteem on the correlation between CM (mainly PA subtype) and intensity of depression. We therefore had to consider a potential link between self-esteem and (i) CM mainly PA and (ii) intensity of depression. The association between PA and self-esteem levels (Rosenberg score) was significant $(\beta=-0.472, \mathrm{p}<0.01)$. Selfesteem levels (Rosenberg score) were associated with the intensity of depression symptoms 
Table 1. Population characteristics.

\begin{tabular}{|c|c|c|c|c|c|c|c|c|c|}
\hline & \multicolumn{4}{|c|}{ General population } & \multicolumn{2}{|c|}{ EOD } & \multicolumn{2}{|c|}{ LOD } & \multirow[b]{2}{*}{$\mathbf{p}$} \\
\hline & $\mathbf{N}$ & Min. & Max. & Mean (SD) & $\mathbf{N}$ & Mean (SD) & $\mathbf{N}$ & Mean $(\mathrm{SD})$ & \\
\hline AGE, years & 96 & 60 & 84 & $67.25(5.67)$ & $50(52.1 \%)$ & $65.66(5.44)$ & $25(26 \%)$ & $69.8(5.77)$ & $.003^{t}$ \\
\hline Female (\%) & $60(62.5 \%)$ & & & & 34 & & 12 & & .094 \\
\hline Marital status (\%) & & & & & & & & & $.017^{\mathrm{c}}$ \\
\hline Single & $8(8.3 \%)$ & & & & 7 & & 0 & & \\
\hline Married & $62(64.6 \%)$ & & & & 27 & & 20 & & \\
\hline Separated & $2(2.1 \%)$ & & & & 2 & & 0 & & \\
\hline Divorced & $10(10.4 \%)$ & & & & 8 & & 1 & & \\
\hline Widowed & $3(3.1 \%)$ & & & & 0 & & 2 & & \\
\hline Educational level & & & & & & & & & $.429^{\mathrm{c}}$ \\
\hline Elementary school diploma & $23(23.8 \%)$ & & & & 10 & & 9 & & \\
\hline High school diploma & $11(11.5 \%)$ & & & & 4 & & 3 & & \\
\hline Youth training (National Vocational Qualification-Level 1,2) & $7(7.3 \%)$ & & & & 3 & & 1 & & \\
\hline Business and Technology Education Council first diploma & $10(10.4 \%)$ & & & & 4 & & 3 & & \\
\hline High school diploma +1 & $3(3.1 \%)$ & & & & 3 & & 0 & & \\
\hline High school diploma +2 & $9(9.4 \%)$ & & & & 7 & & 2 & & \\
\hline High school diploma +3 & $6(6.3 \%)$ & & & & 2 & & 2 & & \\
\hline High school dipoma +4 & $4(4.2 \%)$ & & & & 4 & & 0 & & \\
\hline High school diploma +5 & $5(5.2 \%)$ & & & & 3 & & 1 & & \\
\hline Doctoral Degree & $6(6.3 \%)$ & & & & 4 & & 1 & & \\
\hline LOD & $25(26 \%)$ & & & & & & & & \\
\hline MADRS score M0 & 92 & 8 & 44 & $28.2(7.49)$ & 47 & $29.34(8.02)$ & 25 & $27.28(6.16)$ & $.23^{\mathrm{t}}$ \\
\hline QIDS-SR M0 & 89 & 1 & 26 & $16.53(4.94)$ & 47 & $17(4.95)$ & 23 & $16.43(4.5)$ & $.646^{\mathrm{t}}$ \\
\hline Rosenberg score M0 & 79 & 10 & 36 & $22.47(6.26)$ & 39 & $22.31(6.25)$ & 21 & $22.38(6.43)$ & $.966^{\mathrm{t}}$ \\
\hline BFI extraversion & 78 & 1 & 4.25 & $2.37(.83)$ & 41 & $2.28(.77)$ & 20 & $2.47(.73)$ & $.384^{\mathrm{t}}$ \\
\hline BFI agreeableness & 78 & 3.20 & 5 & $4.14(.46)$ & 41 & $4.25(.42)$ & 20 & $3.97(.45)$ & $.02^{\mathrm{t}}$ \\
\hline BFI neuroticism & 73 & 2 & 5 & $3.85(.63)$ & 40 & $3.96(.53)$ & 20 & $3.7(.72)$ & $.119^{\mathrm{t}}$ \\
\hline BFI conscientiousness & 73 & 1.22 & 4.89 & $3.5(.75)$ & 40 & $3.7(.73)$ & 20 & $3.31(.75)$ & $.061^{\mathrm{t}}$ \\
\hline BFI openness & 78 & 1.10 & 4.80 & $2.8(.86)$ & 41 & $2.96(.83)$ & 20 & $2.45(.84)$ & $.027^{\mathrm{t}}$ \\
\hline CTQ total score & 82 & 25 & 78 & $37.35(9.69)$ & 44 & $38.86(11.62)$ & 21 & $35.57(5.57)$ & $.128^{\mathrm{t}}$ \\
\hline Emotional Abuse & 82 & 5 & 10 & $5.51(1.07)$ & 44 & $5.55(1.23)$ & 21 & $5.52(.75)$ & $.999^{\mathrm{t}}$ \\
\hline Physical Abuse & 82 & 5 & 22 & $11.48(4.28)$ & 44 & $12.18(4.68)$ & 21 & $11(3.42)$ & $.999^{\mathrm{t}}$ \\
\hline Sexual Abuse & 82 & 5 & 15 & $7.2(2.51)$ & 44 & $7.05(2.52)$ & 21 & $7.38(2.4)$ & $.999^{\mathrm{t}}$ \\
\hline Emotional Neglect & 82 & 5 & & $5.35(1.85)$ & 44 & $5.43(2.44)$ & 21 & $5.19(.68)$ & $.999^{\mathrm{t}}$ \\
\hline Physical Neglect & 82 & 5 & & $7.82(3.65)$ & 44 & $8.66(4.44)$ & 21 & $6.48(1.54)$ & $.025^{t}$ \\
\hline
\end{tabular}

BFI: Big Five Inventory

C: Chi2 test; CTQ: Childhood Trauma Inventory; EOD: Early Onset Depression; LOD: Late Onset Depression; M0: Month 0; MADRS: Montgomery-Asberg Depression Rating Scale; Max.: Maximum; Min.: Minimum; N: Number; QIDS-SR: Quick Inventory Depression Scale-Self Report; SD: Standard Deviation

t: t-test.

https://doi.org/10.1371/journal.pone.0250148.t001

(MADRS: $\beta=-0.675, p<0.001$; QIDS: $\beta=-0.375, p<0.001$ ). Therefore, we looked at a potential mediator effect of self-esteem on the correlation between PA and intensity of depression (Hayes' model). We showed that self-esteem (Rosenberg scale) significantly mediated the effect of PA on the severity of depressive symptoms: MADRS: $b=0.318,95 \%$ BCa C.I. $[0.07,0.62]$; QIDS-SR: $b=0.177,95 \%$ BCa C.I. [0.04, 0.37]. We documented Preacher \& Kelly's Kappa Squared values of $19.1 \%\left(k^{2}=0.191\right)$ and $16 \%\left(k^{2}=0.16\right)$, respectively for the two scales, 
Table 2. Difference in the intensity of depression symptoms on comparing the difference in terms of marital status.

\begin{tabular}{c|c|c|c}
\hline & Marital status & Depressive intensity & p $=0.481^{\mathrm{a}}$ \\
\hline MADRS (SD) & Married & $28.4(7.2)$ & $25(9.41)$ \\
\hline & Single & $31.5(13.44)$ & \\
\hline & Separated & $31.63(7.13)$ & $29(5.67)$ \\
\hline QIDS-SR (SD) & Divorced & $16.7(4.4)$ & $\mathrm{p}=0.676^{\mathrm{a}}$ \\
\hline & Widowed & $14.25(8.48)$ & $17.5(7.78)$ \\
\hline
\end{tabular}

MADRS: Montgomery-Asberg Depression Rating Scale; QIDS-SR: Quick Inventory Depression Scale-Self Report; SD: Standard Deviation a: ANOVA.

indicating a moderate effect of the mediation (Fig 4). The mediation indices were found to be 0.182 [95\% CI: 0.042; 0.338] for MADRS and 0.148 [95\% CI: 0.031; 0.292] for QIDS-SR. Therefore, self-esteem had a moderate total mediation effect. The indirect effect of PA on depressive symptom intensity was significant (MADRS: $\beta=0.318,95 \% \mathrm{CI}[0.07 ; 0.624]$, QIDS: $\beta=0.177$ : $95 \% \mathrm{CI}[0.036 ; 0.377])$. The direct effect of PA on depression symptom severity was a positive, but not statistically significant, association when focusing on MADRS $(\beta=0.263, \mathrm{p}=0.132)$. However, the correlation was both positive and significant when focusing on QIDS-SR $(\beta=$ $0.285, \mathrm{p}<0.05)$. The full model effect of PA on intensity of depression symptoms was significant (MADRS: $\beta=0.582, p<0.01$; QIDS: $\beta=0.463, p<0.001$ ) (Fig 4). Self-esteem appeared to mediate the association between PA in childhood and depression symptom severity.

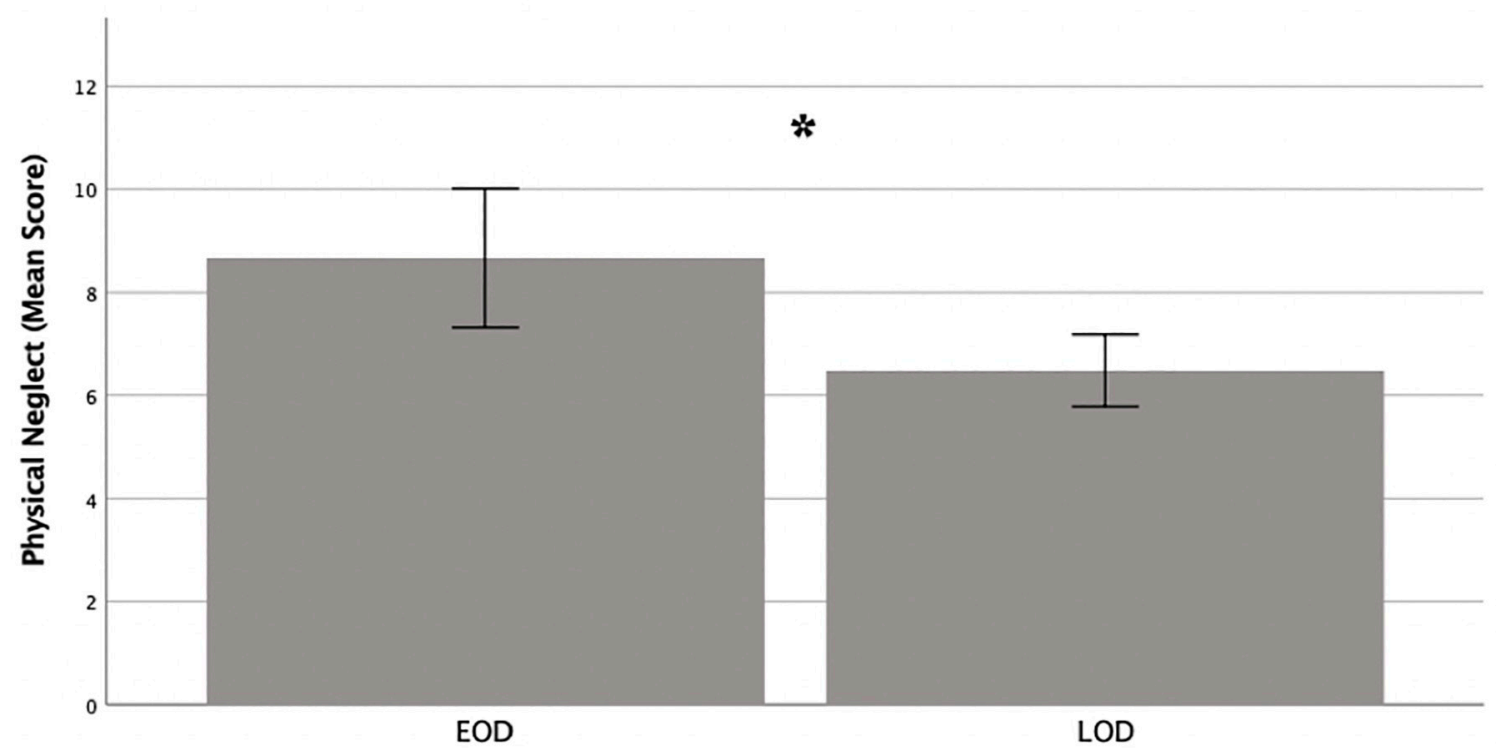

Onset of Depression

Fig 1. Difference of physical neglect between patients with Early Onset Depression (EOD) and Late Onset Depression (LOD). https://doi.org/10.1371/journal.pone.0250148.g001 
Table 3. Association between the intensity of depressive disorder and childhood trauma at baseline.

\begin{tabular}{|c|c|c|c|c|c|}
\hline & & \multicolumn{2}{|c|}{ Unadjusted } & \multicolumn{2}{|c|}{ Adjusted $^{\mathrm{a}}$} \\
\hline & & $\boldsymbol{\beta}$ & p-value* & $\boldsymbol{\beta}$ & p-value ${ }^{*}$ \\
\hline \multirow[t]{6}{*}{ MADRS, score } & CTQ, total score & 0.3 & 0.04 & 0.274 & 0.07 \\
\hline & Emotional abuse, score & 0.049 & 0.999 & 0.032 & 0.999 \\
\hline & Physical abuse, score & 0.328 & 0.02 & 0.304 & 0.03 \\
\hline & Sexual abuse, score & 0.263 & 0.09 & 0.251 & 0.11 \\
\hline & Emotional neglect, score & 0.176 & 0.59 & 0.190 & 0.42 \\
\hline & Physical neglect, score & 0.113 & 0.999 & 0.082 & 0.999 \\
\hline \multirow[t]{6}{*}{ QIDS, score } & CTQ, total score & 0.338 & 0.002 & 0.302 & 0.005 \\
\hline & Emotional abuse, score & 0.105 & 0.999 & 0.075 & 0.999 \\
\hline & Physical abuse, score & 0.392 & 0.002 & 0.362 & 0.005 \\
\hline & Sexual abuse, score & 0.199 & 0.37 & 0.184 & 0.45 \\
\hline & Emotional neglect, score & -0.037 & 0.999 & -0.055 & 0.999 \\
\hline & Physical neglect, score & 0.293 & 0.04 & 0.251 & 0.11 \\
\hline
\end{tabular}

CTQ: Child Trauma Questionnaire; MADRS: Montgomery-Åsberg Depression Rating Scale; QIDS: Quick Inventory of Depressive Symptomatology;

a Age and sex;

${ }^{*}$ Bonferroni corrections.

https://doi.org/10.1371/journal.pone.0250148.t003

\section{Discussion}

To our knowledge, this is the first study in a geriatric TRD population to document an association between $\mathrm{CM}$, specifically related to $\mathrm{PA}$, and the intensity of depressive symptoms, using either self- or hetero-evaluations. Moreover, we found that self-esteem can influence the association between CM and depressive symptom severity scored with MADRS and partially with

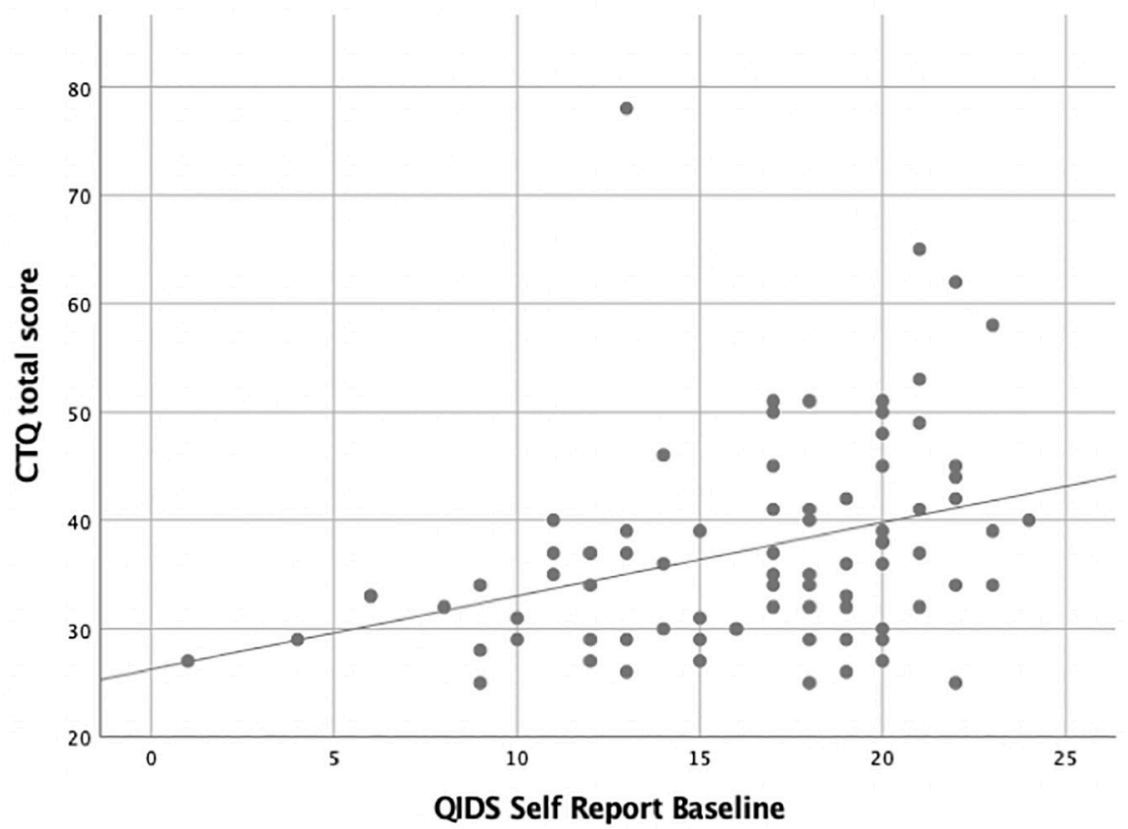

Fig 2. Association between Childhood trauma and intensity of self-reported depressive symptoms. 


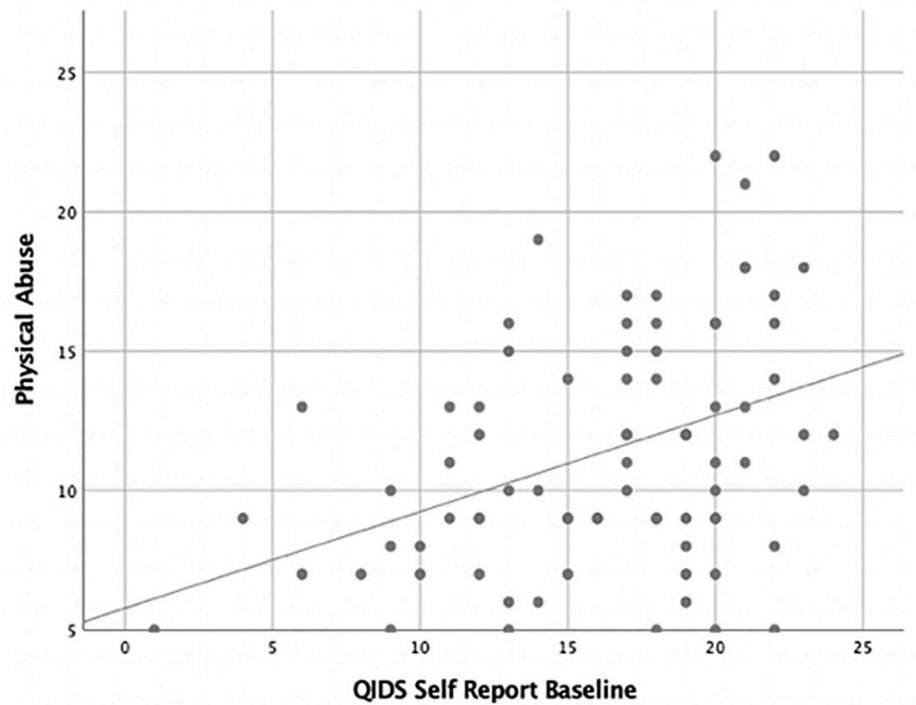

A

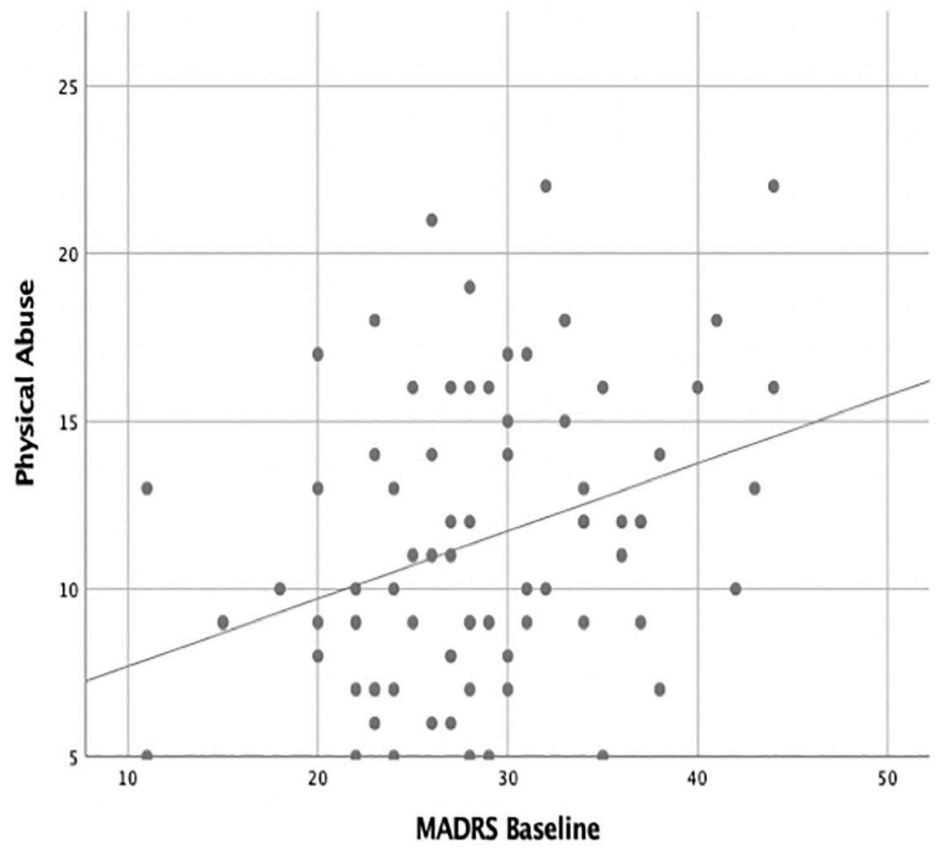

B

Fig 3. Association between Physical Abuse and intensity of depressive symptoms (A: QIDS-SR; B: MADRS). https://doi.org/10.1371/journal.pone.0250148.g003

QIDS-SR. Our findings suggest therefore that low self-esteem is an important factor in geriatric depression, especially in individuals with a history of PA.

To date, the only available study focusing on the correlation between CM and TRD is Tunnard et al. [14]. However, this study was not conducted in the field of geriatric depression since the recruited population was particularly heterogeneous and included both unipolar and 
Table 4. Association between childhood maltreatment and personality traits.

\begin{tabular}{l|c|c|c}
\hline & & $\boldsymbol{\beta}$ & $\mathbf{p}^{-v a l u e^{*}}$ \\
\hline CTQ, total score & neuroticism & 0.223 & 0.07 \\
\hline & extraversion & -0.191 & 0.13 \\
\hline & agreeableness & 0.052 & 0.68 \\
\hline & openness & -0.058 & 0.63 \\
\hline & conscientiousness & -0.204 & 0.11 \\
\hline
\end{tabular}

CTQ: Child Trauma Questionnaire

* Bonferroni corrections.

https://doi.org/10.1371/journal.pone.0250148.t004

bipolar patients. They reported that CM is common, affecting up to $62 \%$ of TRD patients. However, they failed to show any significant correlation between CM and clinical severity.

Moreover, self-esteem has been shown to be associated with geriatric depression symptoms [15] and prognosis [17]. Numerous studies have documented a strong positive correlation between CM and low self-esteem [36-38]. This association could be explained by the fact that early maltreatment can negatively affect the overall cognitive, social and emotional development of children. Also, it is well-established that low self-esteem and depression are closely linked [36-38]. Finally, self-esteem was found to peak in people in their fifties or sixties before decreasing dramatically thereafter. Two explanations for this decline have been put forward $[39,40]$. The first refers to the loss of elements associated with self-esteem, ranging from socioeconomic positions or social roles due to retirement to abilities such as physical and cognitive performance, etc. The second relates to profound changes in attitudes toward oneself in that elderly people tend to accept their limitations as they get older, which leads them to take a more modest view of themselves.

In contrast to previously published studies $[1,6,7]$, we found no significant correlation with personality traits in our work focusing specifically on TRD in the geriatric population. Our study sample was selected from highly specialised care centres in contrast to other published studies that focused on samples from the general population $[1,6,7]$.

There were some limitations. Firstly, our sample was smaller than that of other studies carried out in geriatric populations $[1,6,7]$. This could account for the lack of correlation between CM and personality traits. Moreover, we did not compare our results to a control group of depressed patients showing no resistance to treatment, in order to assess whether

Table 5. Association between self-esteem and childhood trauma at baseline.

\begin{tabular}{|c|c|c|c|c|c|}
\hline & & \multicolumn{2}{|c|}{ Unadjusted } & \multicolumn{2}{|c|}{ Adjusted $^{\mathrm{a}}$} \\
\hline & & $\boldsymbol{\beta}$ & p-value* & $\boldsymbol{\beta}$ & p-value* \\
\hline \multirow[t]{6}{*}{ Rosenberg, score } & CTQ, total score & -0.25 & 0.035 & -0.25 & 0.036 \\
\hline & Emotional abuse, score & 0.11 & 0.99 & 0.11 & 0.99 \\
\hline & Physical abuse, score & -0.31 & 0.04 & -0.32 & 0.04 \\
\hline & Sexual abuse, score & -0.27 & 0.12 & -0.27 & 0.1 \\
\hline & Emotional neglect, score & -0.06 & 0.999 & -0.05 & 0.999 \\
\hline & Physical neglect, score & -0.12 & 0.999 & -0.11 & 0.999 \\
\hline
\end{tabular}

CTQ: Child Trauma Questionnaire; MADRS: Montgomery-Åsberg Depression Rating Scale; QIDS: Quick Inventory of Depressive Symptomatology; STAI: State-Trait Anxiety Inventory;

${ }^{\text {a }}$ Age and sex

* Bonferroni corrections.

https://doi.org/10.1371/journal.pone.0250148.t005 

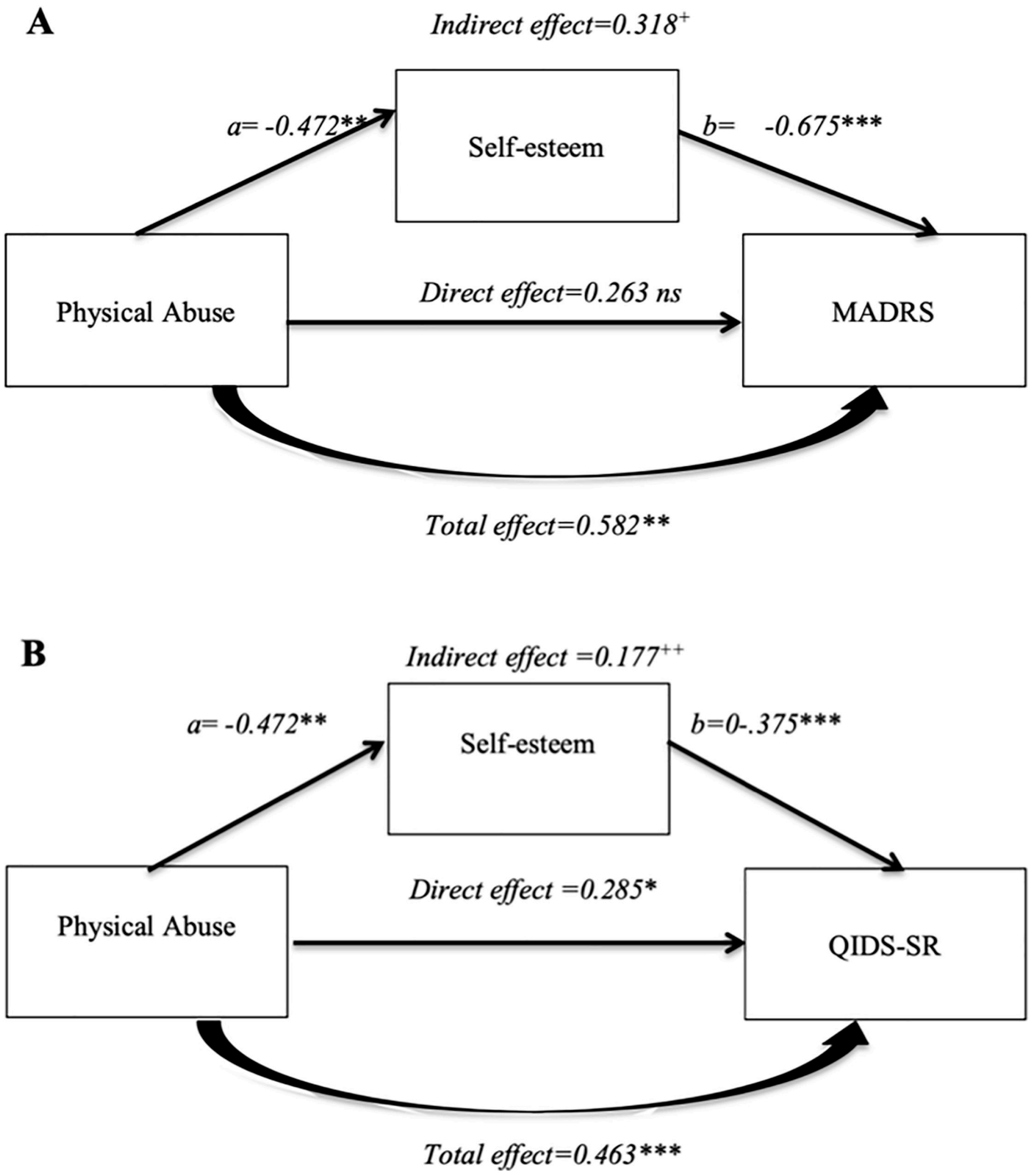

Fig 4. Self-esteem as mediator of physical abuse on intensity of depressive symptoms: A: MADRS; B: QIDS. 
mediation through self-esteem is closely related to TRD. In addition to this, the cut-off age we used for geriatric depression was relatively young (60 years of age and above). However, this cut-off is the same as that used in other studies $[1,6,7]$. In addition, the diagnoses of EOD and LOD were determined retrospectively. This may have introduced a bias and may explain the lack of data in relation to the first major depressive episode. There could also be a recall bias regarding CTQ. Indeed, a recall bias, or greater likelihood of reporting exposure in participants with MDD, has been highlighted due to negative bias in autobiographical memory [41]. Moreover, the mediation analysis should be interpreted with caution given the fact that this was a cross-sectional study. Finally, the involvement of other factors such as cognitive decline and traumatic events occurring in adulthood, which could be linked to the intensity of depressive symptoms, at least in part, would require further investigation in research carried out in geriatric TRD populations.

Despite the need for future studies to confirm our findings, it seems important to take the mediation effect of self-esteem into account in routine clinical practice. Indeed, relevant data indicate the positive effect of psychotherapy, such as cognitive-behavioural therapy (CBT), on low self-esteem [42-46]. Therefore, CBT focused on self-esteem could be particularly useful for the management of TRD, especially in patients with early negative life experiences. In fact, given that higher self-esteem is significantly correlated with better treatment responses, increased self-esteem could improve the medical care outcome [47, 48].

\section{Conclusion}

We highlighted a correlation between CM mainly related to PA and the intensity of depressive symptoms in a geriatric TRD population. Our findings must be confirmed in well-designed prospective studies on larger pathological populations. However, these results underpin the potential relevance of CBT predominantly focused on self-esteem as an add-on psychological intervention useful for managing TRD in geriatric populations, especially in cases who experienced CM.

\section{Supporting information}

S1 Data.

(XLSX)

\section{Acknowledgments}

FondaMental Advanced Centres of Expertise (FACE-DR) collaborators

List of FondaMental Advanced Centres of Expertise (FACE-DR) collaborators: FACE-DR Clinical Coordinating Centre (Fondation FondaMental); B. Aouizerate*, D. Bennabi, M. Leboyer, E. Haffen and PM Llorca; FACE-DR Data Coordinating Centre (Fondation FondaMental): V. Barteau, S. Bensalem, H. Laouamri, and Karmene Souryis; FACE-DR Clinical Sites and Principal Collaborators in France; AP-HP, DHU PePSY, Pôle de Psychiatrie et d'Addictologie des Hôpitaux Universitaires (University Hospital Psychiatry and Addictology Cluster) H Mondor, Créteil; L. Mallet, L. Yon, J. Petrucci and JB. Genty; Service de Psychiatrie et de Psychologie Médicale de l'adulte, Centre Expert Dépression Résistante FondaMental, CHRU de Toulouse, Hôpital Purpan, Toulouse, France: A. Yrondi, D Pierre, L Schmitt and C. Scotto d'Apollonia; Service de Psychiatrie clinique, Centre Expert Dépression Résistante FondaMental, EA 481 Neurosciences, Université de Bourgogne Franche Comté, Besançon, France: E. Haffen, Djamila Bennabi, I. Ryff, E. Beuchet, G. Tio, C. Cappe and E. Clerc; Service de Psychiatrie de l'adulte B, Centre Expert Dépression Résistante FondaMental, CHU de Clermont- 
Ferrand, Clermont-Ferrand, France: PM. Llorca, M. Garnier, RM Honciuc, E Allauze and O. Blanc; Service de Psychiatrie adulte, Centre Expert Dépression Résistante FondaMental, Hôpital Fernand-Widal, Paris, France: F. Bellivier, N. Allaili, I. Nieto, J. Meheust, Y. Sunthavy and J. Maruani; Service de Psychiatrie de l'adulte, CS 10217, Centre Expert Dépression Résistante FondaMental, CHU de Grenoble, Hôpital Nord, Grenoble, France: T. Bougerol, M. Polosan, P. Courvoisier, J. Holtzmann, B. Fredembach and S. Foubert-Andreani; Clinique Psychiatrique Universitaire (University Psychiatric Clinic), Centre Expert Dépression Résistante FondaMental, Inserm U1253 Imaging and Brain: iBrain, CHRU de Tours, Tours, France: V. Camus and W. El Hage; Service Universitaire de Psychiatrie adulte, Centre Expert Dépression Résistante FondaMental, Centre Hospitalier Le Vinatier, Bron cedex, France: T. D’Amato, F. Haesebaert, C. Dubien, M. Lefebvre, A. Meznad, J. Brunelin and R. Moirand; Pôle de Psychiatrie Générale et Universitaire, Centre Expert Dépression Résistante FondaMental, CH Charles Perrens, Bordeaux, France: B. Aouizerate and O. Doumy; Pôle Psychiatrie, Centre Expert Dépression Résistante FondaMental, CHU La Conception, Marseille, France: C. Lancon, R. Richieri, P. Peri, M. Faugere and C. Faget-Agius; Département des Urgences et Post-Urgences Psychiatriques (Psychiatric Emergency and Post-Emergency Department), Centre Expert Dépression Résistante FondaMental, CHRU Lapeyronie, Montpellier, France: P. Courtet, JP. Boulenger and F. Moliere; Service de Psychiatrie de l'adulte, Centre Expert Dépression Résistante FondaMental, CHU de Brest, Hôpital de Bohars, Bohars, France: F. Stephan, M. Walter and C. Mesmeur; Service de Psychiatrie adulte, Centre Expert Dépression Résistante FondaMental,

CHRU de Lille, Hôpital Fontan 1, Lille, France: G. Vaiva, and M Horn.

*lead author for this group: bruno.aouizerate@u-bordeaux.fr

\section{Author Contributions}

Conceptualization: Antoine Yrondi, Christophe Arbus, Djamila Bennabi, Bruno Aouizerate, Wissam El-Hage.

Formal analysis: Antoine Yrondi.

Funding acquisition: Marion Leboyer, Emmanuel Haffen.

Investigation: Antoine Yrondi, Christophe Arbus, Djamila Bennabi, Thierry D’Amato, Philippe Courtet, Olivier Doumy, Jean-Baptiste Genty, Jérôme Holtzmann, Mathilde Horn, Christophe Lancon, Marion Leboyer, Pierre-Michel Llorca, Julia Maruani, Rémi Moirand, Fanny Molière, Jean Petrucci, Raphaelle Richieri, Ludovic Samalin, Florian Stephan, Guillaume Vaiva, Michel Walter, Emmanuel Haffen, Bruno Aouizerate, Wissam El-Hage.

Methodology: Antoine Yrondi, Christophe Arbus, Djamila Bennabi, Frank Bellivier, Thierry Bougerol, Vincent Camus, Philippe Courtet, Olivier Doumy, Jean-Baptiste Genty, Jérôme Holtzmann, Mathilde Horn, Pierre-Michel Llorca, Ludovic Samalin, Guillaume Vaiva, Bruno Aouizerate, Wissam El-Hage.

Project administration: Antoine Yrondi, Pierre-Michel Llorca, Emmanuel Haffen, Wissam El-Hage.

Supervision: Christophe Arbus, Thierry D'Amato, Frank Bellivier, Thierry Bougerol, Vincent Camus, Olivier Doumy, Christophe Lancon, Marion Leboyer, Pierre-Michel Llorca, Bruno Aouizerate, Wissam El-Hage.

Validation: Christophe Arbus, Djamila Bennabi, Thierry D’Amato, Frank Bellivier, Thierry Bougerol, Vincent Camus, Philippe Courtet, Jean-Baptiste Genty, Jérôme Holtzmann, Mathilde Horn, Christophe Lancon, Marion Leboyer, Pierre-Michel Llorca, Julia Maruani, Rémi Moirand, Fanny Molière, Jean Petrucci, Raphaelle Richieri, Ludovic Samalin, Florian 
Stephan, Guillaume Vaiva, Michel Walter, Emmanuel Haffen, Bruno Aouizerate, Wissam El-Hage.

Visualization: Philippe Courtet.

Writing - original draft: Antoine Yrondi, Christophe Arbus, Djamila Bennabi, Bruno Aouizerate, Wissam El-Hage.

Writing - review \& editing: Christophe Arbus, Djamila Bennabi, Thierry D’Amato, Frank Bellivier, Thierry Bougerol, Vincent Camus, Philippe Courtet, Olivier Doumy, Jean-Baptiste Genty, Jérôme Holtzmann, Mathilde Horn, Christophe Lancon, Marion Leboyer, Pierre-Michel Llorca, Julia Maruani, Rémi Moirand, Fanny Molière, Jean Petrucci, Raphaelle Richieri, Ludovic Samalin, Florian Stephan, Guillaume Vaiva, Michel Walter, Emmanuel Haffen.

\section{References}

1. Gomes Jardim GB, von Gunten A, da Silva Filho IG, Ziegelmann PK, Bumaguin DB, Nogueira EL, et al. Relationship between childhood maltreatment and geriatric depression: the mediator effect of personality traits. Int Psychogeriatr. 2019; 1-9. https://doi.org/10.1017/S1041610219000073 PMID: 30827285

2. Sachs-Ericsson N, Corsentino E, Moxley J, Hames JL, Rushing NC, Sawyer K, et al. A longitudinal study of differences in late- and early-onset geriatric depression: depressive symptoms and psychosocial, cognitive, and neurological functioning. Aging Ment Health. 2013; 17: 1-11. https://doi.org/10. 1080/13607863.2012.717253 PMID: 22934752

3. Blazer DG. Depression in late life: review and commentary. J Gerontol A Biol Sci Med Sci. 2003; 58: 249-265. https://doi.org/10.1093/gerona/58.3.m249 PMID: 12634292

4. Brodaty H, Luscombe G, Parker G, Wilhelm K, Hickie I, Austin MP, et al. Early and late onset depression in old age: different aetiologies, same phenomenology. J Affect Disord. 2001; 66: 225-236. https:// doi.org/10.1016/s0165-0327(00)00317-7 PMID: 11578676

5. van Krugten FCW, Kaddouri M, Goorden M, van Balkom AJLM, Bockting CLH, Peeters FPML, et al. Indicators of patients with major depressive disorder in need of highly specialized care: A systematic review. PLoS One. 2017; 12: e0171659. https://doi.org/10.1371/journal.pone.0171659 PMID: 28178306

6. Comijs HC, van Exel E, van der Mast RC, Paauw A, Oude Voshaar R, Stek ML. Childhood abuse in late-life depression. J Affect Disord. 2013; 147: 241-246. https://doi.org/10.1016/j.jad.2012.11.010 PMID: 23196199

7. Wielaard I, Hoyer M, Rhebergen D, Stek ML, Comijs HC. Childhood abuse and late-life depression: Mediating effects of psychosocial factors for early- and late-onset depression. Int J Geriatr Psychiatry. 2018; 33: 537-545. https://doi.org/10.1002/gps.4828 PMID: 29318648

8. Fava M, Davidson KG. Definition and epidemiology of treatment-resistant depression. Psychiatr Clin North Am. 1996; 19: 179-200. https://doi.org/10.1016/s0193-953x(05)70283-5 PMID: 8827185

9. Rush AJ, Trivedi MH, Wisniewski SR, Nierenberg AA, Stewart JW, Warden D, et al. Acute and longerterm outcomes in depressed outpatients requiring one or several treatment steps: a STAR*D report. Am J Psychiatry. 2006; 163: 1905-1917. https://doi.org/10.1176/ajp.2006.163.11.1905 PMID: 17074942

10. Greden JF. The burden of disease for treatment-resistant depression. J Clin Psychiatry. 2001; 62 Suppl 16: 26-31. PMID: 11480881

11. Olsen LR, Mortensen EL, Bech P. Prevalence of major depression and stress indicators in the Danish general population. Acta Psychiatr Scand. 2004; 109: 96-103. https://doi.org/10.1046/j.0001-690x. 2003.00231.x PMID: 14725589

12. Bennabi D, Yrondi A, Charpeaud T, Genty J-B, Destouches S, Lancrenon S, et al. Clinical guidelines for the management of depression with specific comorbid psychiatric conditions French recommendations from experts (the French Association for Biological Psychiatry and Neuropsychopharmacology and the fondation FondaMental). BMC Psychiatry. 2019; 19: 50. https://doi.org/10.1186/s12888-019-2025-7 PMID: 30700272

13. Kaplan MJ, Klinetob NA. Childhood emotional trauma and chronic posttraumatic stress disorder in adult outpatients with treatment-resistant depression. J Nerv Ment Dis. 2000; 188: 596-601. https://doi.org/ 10.1097/00005053-200009000-00006 PMID: 11009333 
14. Tunnard C, Rane LJ, Wooderson SC, Markopoulou K, Poon L, Fekadu A, et al. The impact of childhood adversity on suicidality and clinical course in treatment-resistant depression. J Affect Disord. 2014; 152-154: 122-130. https://doi.org/10.1016/j.jad.2013.06.037 PMID: 23880448

15. Szanto K, Galfalvy H, Vanyukov PM, Keilp JG, Dombrovski AY. Pathways to Late-Life Suicidal Behavior: Cluster Analysis and Predictive Validation of Suicidal Behavior in a Sample of Older Adults With Major Depression. J Clin Psychiatry. 2018; 79. https://doi.org/10.4088/JCP.17m11611 PMID: 29489076

16. Tosangwarn $\mathrm{S}$, Clissett $\mathrm{P}$, Blake $\mathrm{H}$. Predictors of depressive symptoms in older adults living in care homes in Thailand. Arch Psychiatr Nurs. 2018; 32: 51-56. https://doi.org/10.1016/j.apnu.2017.09.010 PMID: 29413072

17. Gildengers AG, Houck PR, Mulsant BH, Dew MA, Aizenstein HJ, Jones BL, et al. Trajectories of treatment response in late-life depression: psychosocial and clinical correlates. J Clin Psychopharmacol. 2005; 25: S8-13. https://doi.org/10.1097/01.jcp.0000161498.81137.12 PMID: 16027561

18. Lereya ST, Copeland WE, Costello EJ, Wolke D. Adult mental health consequences of peer bullying and maltreatment in childhood: two cohorts in two countries. Lancet Psychiatry. 2015; 2: 524-531. https://doi.org/10.1016/S2215-0366(15)00165-0 PMID: 26360448

19. Orri M, Boivin M, Chen C, Ahun MN, Geoffroy M-C, Ouellet-Morin I, et al. Cohort Profile: Quebec Longitudinal Study of Child Development (QLSCD). Soc Psychiatry Psychiatr Epidemiol. 2020. https://doi. org/10.1007/s00127-020-01972-z PMID: 33185737

20. Dagnino P, Ugarte MJ, Morales F, González S, Saralegui D, Ehrenthal JC. Risk Factors for Adult Depression: Adverse Childhood Experiences and Personality Functioning. Front Psychol. 2020; 11: 594698. https://doi.org/10.3389/fpsyg.2020.594698 PMID: 33362658

21. Santangelo PS, Kockler TD, Zeitler M-L, Knies R, Kleindienst N, Bohus M, et al. Self-esteem instability and affective instability in everyday life after remission from borderline personality disorder. Borderline Personal Disord Emot Dysregul. 2020; 7: 25. https://doi.org/10.1186/s40479-020-00140-8 PMID: 33292714

22. Yrondi A, Bennabi D, Haffen E, Garnier M, Bellivier F, Bourgerol T, et al. Significant Need for a French Network of Expert Centers Enabling a Better Characterization and Management of Treatment-Resistant Depression (Fondation FondaMental). Front Psychiatry. 2017; 8: 244. https://doi.org/10.3389/fpsyt. 2017.00244 PMID: 29225582

23. Yrondi A, Aouizerate B, Bennabi D, Richieri R, D'Amato T, Bellivier F, et al. Childhood maltreatment and clinical severity of treatment-resistant depression in a French cohort of outpatients (FACE-DR): One-year follow-up. Depress Anxiety. 2020; 37: 365-374. https://doi.org/10.1002/da.22997 PMID: 31999402

24. Thase ME, Rush AJ. When at first you don't succeed: sequential strategies for antidepressant nonresponders. J Clin Psychiatry. 1997;58 Suppl 13: 23-29. PMID: 9402916

25. Novelo M, von Gunten A, Gomes Jardim GB, Spanemberg L, Argimon de L II, Nogueira EL. Effects of childhood multiple maltreatment experiences on depression of socioeconomic disadvantaged elderly in Brazil. Child Abuse Negl. 2018; 79: 350-357. https://doi.org/10.1016/j.chiabu.2018.02.013 PMID: 29522996

26. Kuhlman KR, Maercker A, Bachem R, Simmen K, Burri A. Developmental and contextual factors in the role of severe childhood trauma in geriatric depression: the sample case of former indentured child laborers. Child Abuse Negl. 2013; 37: 969-978. https://doi.org/10.1016/j.chiabu.2013.04.013 PMID: 23747018

27. Shin C, Park MH, Lee S-H, Ko Y-H, Kim Y-K, Han K-M, et al. Usefulness of the 15-item geriatric depression scale (GDS-15) for classifying minor and major depressive disorders among community-dwelling elders. J Affect Disord. 2019; 259: 370-375. https://doi.org/10.1016/j.jad.2019.08.053 PMID: 31470180

28. Raposo SM, Mackenzie CS, Henriksen CA, Afifi TO. Time does not heal all wounds: older adults who experienced childhood adversities have higher odds of mood, anxiety, and personality disorders. Am J Geriatr Psychiatry. 2014; 22: 1241-1250. https://doi.org/10.1016/j.jagp.2013.04.009 PMID: 24012227

29. Frances A, Pincus HA, First MB. AMERICAN PSYCHIATRIC ASSOCIATION DSM-IV-TR. 4ème édition texte révisé. Washongton DC; 2000. Available: http://dsm.psychiatryonline.org/content.aspx? bookid=22\&sectionid $=1890370$

30. Montgomery SA, Asberg M. A new depression scale designed to be sensitive to change. Br J Psychiatry. 1979; 134: 382-389. https://doi.org/10.1192/bjp.134.4.382 PMID: 444788

31. Rush AJ, Trivedi MH, Ibrahim HM, Carmody TJ, Arnow B, Klein DN, et al. The 16-Item Quick Inventory of Depressive Symptomatology (QIDS), clinician rating (QIDS-C), and self-report (QIDS-SR): a psychometric evaluation in patients with chronic major depression. Biol Psychiatry. 2003; 54: 573-583. https:// doi.org/10.1016/s0006-3223(02)01866-8 PMID: 12946886 
32. Bernstein DP, Fink L, Handelsman L, Foote J, Lovejoy M, Wenzel K, et al. Initial reliability and validity of a new retrospective measure of child abuse and neglect. Am J Psychiatry. 1994; 151: 1132-1136. https://doi.org/10.1176/ajp.151.8.1132 PMID: 8037246

33. Wongpakaran T, Tinakon W, Wongpakaran N, Nahathai W. A comparison of reliability and construct validity between the original and revised versions of the Rosenberg Self-Esteem Scale. Psychiatry Investig. 2012; 9: 54-58. https://doi.org/10.4306/pi.2012.9.1.54 PMID: 22396685

34. Goldberg LR. An alternative "description of personality": the big-five factor structure. J Pers Soc Psychol. 1990; 59: 1216-1229. https://doi.org/10.1037//0022-3514.59.6.1216 PMID: 2283588

35. Hayes A. Introduction to mediation, moderation, and conditional process analysis: A regression-based approach.: New York: The Guilford Press.; 2013.

36. Schmitz N, Kugler J, Rollnik J. On the relation between neuroticism, self-esteem, and depression: results from the National Comorbidity Survey. Compr Psychiatry. 2003; 44: 169-176. https://doi.org/10. 1016/S0010-440X(03)00008-7 PMID: 12764703

37. Uher R, McGuffin $P$. The moderation by the serotonin transporter gene of environmental adversity in the etiology of depression: 2009 update. Mol Psychiatry. 2010; 15: 18-22. https://doi.org/10.1038/mp. 2009.123 PMID: 20029411

38. Chang R, Wang H, She R, Zhang S, Tsamlag L, Shen Q, et al. Feelings of Entrapment and Defeat Mediate the Association Between Self-Esteem and Depression Among Transgender Women Sex Workers in China. Front Psychol. 2019; 10: 2241. https://doi.org/10.3389/fpsyg.2019.02241 PMID: 31636586

39. Robins RW, Trzesniewski KH. Self-Esteem Development Across the Lifespan. Curr Dir Psychol Sci. 2005; 14: 158-162. https://doi.org/10.1111/j.0963-7214.2005.00353.x

40. Robins RW, Trzesniewski KH, Tracy JL, Gosling SD, Potter J. Global self-esteem across the life span Psychology and Aging. 2002; 17: 423-434. https://doi.org/10.1037/0882-7974.17.3.423 PMID: 12243384

41. Brewin CR, Reynolds $M$, Tata $P$. Autobiographical memory processes and the course of depression. $J$ Abnorm Psychol. 1999; 108: 511-517. https://doi.org/10.1037//0021-843x.108.3.511 PMID: 10466275

42. Griffioen BT, van der Vegt AA, de Groot IW, de Jongh A. The Effect of EMDR and CBT on Low Selfesteem in a General Psychiatric Population: A Randomized Controlled Trial. Front Psychol. 2017; 8 : 1910. https://doi.org/10.3389/fpsyg.2017.01910 PMID: 29167649

43. Kolubinski DC, Frings D, Nikčević AV, Lawrence JA, Spada MM. A systematic review and meta-analysis of CBT interventions based on the Fennell model of low self-esteem. Psychiatry Res. 2018; 267: 296-305. https://doi.org/10.1016/j.psychres.2018.06.025 PMID: 30201116

44. McManus F, Waite $P$, Shafran R. Cognitive-Behavior Therapy for Low Self-Esteem: A Case Example. Cognitive and Behavioral Practice. 2009; 16: 266-275. https://doi.org/10.1016/j.cbpra.2008.12.007

45. Waite $P, M c M a n u s ~ F$, Shafran R. Cognitive behaviour therapy for low self-esteem: a preliminary randomized controlled trial in a primary care setting. J Behav Ther Exp Psychiatry. 2012; 43: 1049-1057. https://doi.org/10.1016/j.jbtep.2012.04.006 PMID: 22683442

46. Rigby L, Waite S. Group Therapy for Self-Esteem, Using Creative Approaches and Metaphor as Clinical Tools. Behavioural and Cognitive Psychotherapy. 2006; 35: 361-364. https://doi.org/10.1017/ S1352465806003389

47. Johnson SL, Meyer B, Winett C, Small J. Social support and self-esteem predict changes in bipolar depression but not mania. J Affect Disord. 2000; 58: 79-86. https://doi.org/10.1016/s0165-0327(99) 00133-0 PMID: 10760562

48. Parker TJ, Page AC, Hooke GR. The influence of individual, group, and relative self-esteem on outcome for patients undergoing group cognitive-behavioural therapy treatment. Br J Clin Psychol. 2013; 52 : 450-463. https://doi.org/10.1111/bjc.12029 PMID: 24117916 